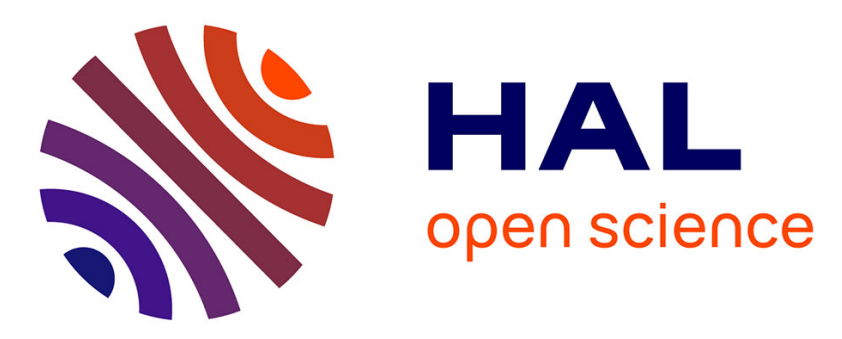

\title{
A Biomimetic Electrocatalytic System for the Atom-Economical Chemoselective Synthesis of Secondary Amines
}

\author{
Martine Largeron, Maurice-Bernard Fleury
}

\section{To cite this version:}

Martine Largeron, Maurice-Bernard Fleury. A Biomimetic Electrocatalytic System for the AtomEconomical Chemoselective Synthesis of Secondary Amines. Organic Letters, 2009, 11 (4), pp.883-886. 10.1021/ol802885b . hal-02384938

\section{HAL Id: hal-02384938 \\ https://hal.science/hal-02384938}

Submitted on 27 Nov 2020

HAL is a multi-disciplinary open access archive for the deposit and dissemination of scientific research documents, whether they are published or not. The documents may come from teaching and research institutions in France or abroad, or from public or private research centers.
L'archive ouverte pluridisciplinaire HAL, est destinée au dépôt et à la diffusion de documents scientifiques de niveau recherche, publiés ou non, émanant des établissements d'enseignement et de recherche français ou étrangers, des laboratoires publics ou privés. 


\title{
A Biomimetic Electrocatalytic System for the Atom-Economical Chemoselective Synthesis of Secondary Amines
}

\author{
Martine Largeron* and Maurice-Bernard Fleury \\ UMR 8638 Synthèse et Structure de Molécules d'Intérêt Pharmacologique, CNRS- \\ Université Paris Descartes, 4 avenue de l'observatoire, 75270 Paris cedex 06, France
}

martine.largeron@parisdescartes.fr

Received Date (will be automatically inserted after manuscript is accepted)

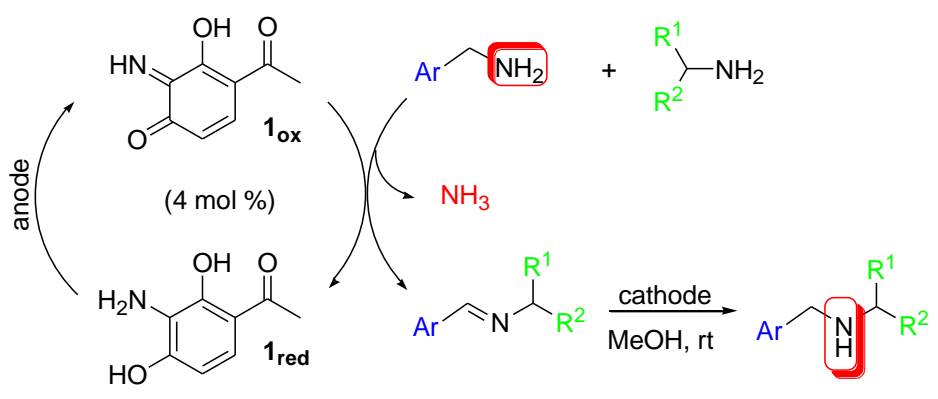

A facile one-pot oxidation-imine formation-reduction route to secondary amines can be achieved electrolytically from primary amines. This atom-economical $1_{\text {ox }}$-mediated sequence, leaving ammonia as the sole by-product, allows the rapid chemoselective synthesis of secondary amines, at both ambient temperature and pressure.

Secondary amines are highly versatile building blocks for various organic substrates and are essential pharmacophores in numerous biologically active compounds. Hence, the development of efficient methods for the synthesis of secondary amines has still been a challenging and active area of research. Conventional synthetic approaches from primary amines include reductive alkylation, protection-deprotection strategy and direct $\mathrm{N}$-alkylation. However, these methods suffer disadvantages such as low functional group tolerance, harsh reaction conditions, lengthy sequences and overalkylation. $^{1}$

(1) For a review on the synthesis of secondary amines, see: Salvatore, R. N.; Yoon, C. H.; Jung, K. W. Tetrahedron 2001, 57, 7785-7811.

(2) For recent reviews on catalytic hydroamination of alkynes and alkenes, see: (a) Severin, R.; Doye, S. Chem. Soc. Rev. 2007, 36, 1407 1420. (b) Müller, T.E.; Hultsch, K. C.; Yus, M.; Foubelo, F.; Tada, M. Chem. Rev. 2008, 108, 3795-3892.
To overcome these limitations, various efficient metalcatalyzed syntheses of secondary amines have been developed in the last decade. Although the hydroamination of alkenes or alkynes ${ }^{2}$ and the amination of aryl halides ${ }^{3}$ are most important, metal-catalyzed $\mathrm{N}$ alkylation of primary amines with alcohols, ${ }^{4}$ amines $^{5}$ or nitriles ${ }^{6}$ represents attractive approaches for the synthesis of secondary amines. A noteworthy example is the selective ruthenium-catalyzed $\mathrm{N}$-alkylation of aryl amines using aliphatic amines which produces the corresponding $N$-alkyl-aryl amines, in high yields, leaving ammonia as the only by-product. ${ }^{5 a}$

(3) For recent reviews on metal catalyzed amination of aryl halides, see : (a) Surry, D. S.; Buchwald, S. L. Angew. Chem. Int. Ed. 2008, 47, 6338-6361. (b) Hartwig, J.F. Nature 2008, 455, 314-322. (c) Hartwig, J.F. Acc. Chem. Res. 2008, 41, 1534-1544. 
The performance of a metal-free in situ oxidation-imine formation-reduction sequence, using manganese dioxide in combination with sodium borohydride or polymersupported cyanoborohydride, has also been reported for the conversion of activated alcohols into secondary amines. $^{7}$

Related routes to secondary amines could also be achieved electrolytically from primary amines, but the fact these ones are oxidized at relatively high anodic potentials $(>+1.5 \mathrm{~V}$ vs SCE), and give rise to unstable cation radicals that rapidly deprotonate and attach to the electrode surface, does not make it possible directly. ${ }^{8}$

Recently, we reported that electrogenerated $o$-iminoquinone $\mathbf{1}_{\mathbf{0 x}}$ acted as an effective biomimetic catalyst for the chemoselective oxidation of primary aliphatic amines, under metal-free conditions. The mechanism was very close to the ionic pyridoxal-like transamination process reported for amine oxidase cofactors (Scheme 1). ${ }^{9}$ The formation of a highly reactive Schiff base cyclic transition state (equation (4), Scheme 1), which allowed the activation of the imine function for further nucleophilic attack by the amine, constituted the driving force for the overall ionic mechanism. ${ }^{9 b}$ The catalytic cycle produced the reduced catalyst $\mathbf{1}_{\text {red }}$ and an unstable alkylimine as the product of amine oxidation, at room temperature, leaving ammonia as the sole by-product. These conditions were particularly favorable for using the imine in situ for further reactions. Accordingly, we recently described the utilization of the tautomeric enamine form of certain in situ generated alkylimines as cycloaddition partner in cascade reactions leading to potent neuroprotective 1,4benzoxazine derivatives. ${ }^{10}$

(4) For selected recent examples see: (a) Fujita, K.-I.; Yamaguchi, R. Synlett 2005, 4, 560-571. (b) Tillack, D.; Hollmann, D.; Michalik, R.; Jackstell, R.; Beller, M. Tetrahedron Lett. 2006, 47, 8881-8885. (c) Hoolman, D.; Tillack, A.; Michalik, D.; Jackstell, R.; Beller, M. Chem. Asian J. 2007, 2, 403-410. (d) Hamid, M. H. S. A.; Williams, M. J. Chem. Commun. 2007, 725-727. (e) Nordstrom, L. U.; Madsen, R. Chem. Commun. 2007, 5034-5036. (f) Fujita, K.-I.; Enoki, Y.; Yamaguchi, R. Tetrahedron 2008, 64, 1943-1954. (g) Yamaguchi, R. Kawagoe, S.; Asai, C.; Fujita, K.-I. Org. Lett. 2008, 10, 181-184. (h) Pontes da Costa, A.; Viciano, M.; Sanau, M.; Merino, S.; Tejeda, J.; Peris, E.; Royo, B. Organometallics 2008, 27, 1305-1309.

(5) (a) Hollmann, D.; Bähn, S.; Tillack, A.; Beller, M. Angew. Chem. Int. Ed. 2007, 46, 8291-8294. (b) Hollmann, D.; Bähn, S.; Tillack, A.; Beller, M. Chem. Commun. 2008, 3199-3201. (c) Hollmann, D.; Bähn, S.; Tillack, A.; Parton, R.; Altink, R.; Beller, M. Tetrahedron Lett. 2008, 49, 5742-5745

(6) Sajiki, H.; Ikawa, T.; Hirota, K. Org. Lett. 2004, 6, 4977-4980.

(7) (a) Blackburn, L.; Taylor, R. J. K. Org. Lett. 2001, 3, 1637-1639. (b) Kanno, H.; Taylor, R. J. K. Tetrahedron Lett. 2002, 43, 7337-7340. (c) Taylor, R. J. K.; Reid, M.; Foot, J.; Raw, S.A. Acc. Chem. Res. 2005, 38, 851-869.

(8) For recent papers, see: (a) Adenier, A.; Chehimi, M. M., Gallardo, I.; Pinson, J., Vilà, N.; Langmuir 2004, 20, 8243-8253. (b) Gallardo, I.; Pinson, J.; Vilà, N. J. Phys. Chem. B 2006, 110, 19521 19529. (c) Bourdelande, J.L.; Gallardo, I. Guirado, G. J. Am. Chem. Soc. 2007, 129, 2817-2821.

(9) (a) Largeron, M.; Neudörffer, A.; Fleury, M.-B. Angew. Chem. Int. Ed. 2003, 42, 1026-1029. (b) Largeron, M.; Chiaroni, A.; Fleury, M.-B. Chem. Eur. J. 2008, 14, 996-1003.

(10) (a) Largeron, M.; Neudörffer, A.; Vuilhorgne, M.; Blattes, E.; Fleury, M.-B. Angew. Chem. Int. Ed. 2002, 41, 824-827. (b) Blattes, E.; Fleury, M.-B.; Largeron, M. J. Org. Chem. 2004, 69, 882-890. (c) Blattes, E.; Lockhart, B.; Lestage, P.; Schwendimann, L.; Gressens, P.; Fleury, M.-B.; Largeron, M. J. Med. Chem. 2005, 48, 1282-1286. (d) Xu, D.; Chiaroni, A.; Fleury, M.-B.; Largeron, M. J. Org. Chem. 2006, 71, 6374-6381.
Next, we decided to investigate the utility of the electrocatalyst $\mathbf{1}_{\mathbf{o x}}$ for the synthesis of secondary amines through the $\mathbf{1}_{\mathbf{o x}}$-mediated catalytic process followed by an electrochemical reduction of the extruded alkylimine. However, the yield of the produced secondary amine could not exceed $50 \%$, because two molecules of primary amine (equations (2) and (5), Scheme 1) are required to produce one molecule of alkylimine (equation (6), Scheme 1). Furthermore, secondary amines possessing different substituents on both sides of the nitrogen atom could not be prepared by this way.

Scheme 1. Ionic transamination mechanism of catalytic oxidation of primary aliphatic amines mediated by electrogenerated $o$-iminoquinone amine oxidase mimic $\mathbf{1}_{\mathbf{o x}}$.
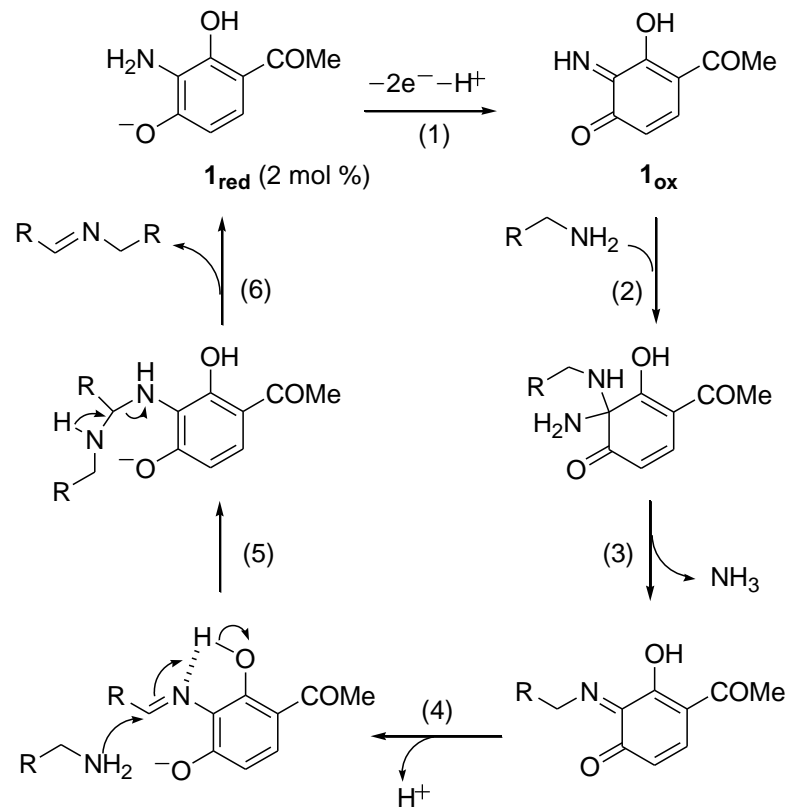

Thus, we envisioned some modifications of our electrocatalytic procedure and we report herein a facile one-pot metal-free $\mathbf{1}_{\mathbf{o x}}$-mediated oxidation-imine formation-reduction sequence for the atom-economical chemoselective $\mathrm{N}$-alkylation of activated primary amines with amines, under mild conditions.

As a starting point of our investigations, we chose to perform the $\mathbf{1}_{\mathbf{o x}}$-mediated catalytic oxidation of an activated primary amine such as benzylamine, in the presence of a non-activated primary amine such as aminomethylcyclopropane, which should serve as the alkylating agent. Upon optimization, we found that a combination of $2.50 \mathrm{mmol}$ of benzylamine with 3.75 mmol of aminomethylcyclopropane and $0.10 \mathrm{mmol}$ of $\mathbf{1}_{\text {red }}$ which corresponds to $4 \mathrm{~mol} \%$ (relative to benzylamine) of the electrocatalyst $\mathbf{1}_{\mathbf{o x}}$, gave the best results. Then, the $\mathbf{1}_{\mathbf{o x}}$-mediated catalytic oxidation step was realized under the previously reported conditions, which required a platinum anode and methanol as the solvent. ${ }^{9 b}$ When the controlled potential of the Pt anode was fixed at $+0.6 \mathrm{~V}$ 
vs SCE, which is at a potential for which $\mathbf{1}_{\text {red }}$ could be oxidized to the iminoquinone form $\mathbf{1}_{\mathbf{0}}$, the anodic current remained constant for a long time, and the current efficiency obtained by electrolysis for $3 \mathrm{~h}$ was $100 \%$, indicating that no side reaction took place under the experimental conditions used. These results confirmed that the $\mathbf{1}_{\mathbf{o x}} / \mathbf{1}_{\text {red }}$ system behaved as a redox mediator for the indirect electrochemical oxidation of benzylamine to the corresponding $N$-benzylidenealkylamine (see the equation in Table 1). The in situ presence of $\mathrm{N}$ benzylidenealkylamine could be evidenced through the UV-vis absorption changes observed in the course of the catalytic anodic process (See Figure 1(a) in the Supporting Information). Effectively, a UV absorption band at $250 \mathrm{~nm}$ developed which was close to that recorded from a solution of commercially available related $N$-benzylidenemethylamine in methanol. In a control experiment, the chemoselectivity of the oxidationimine formation reaction was verified by converting the unstable in situ generated imine to the 2,4dinitrophenylhydrazone (DNPH) by aqueous acidic workup of the oxidized solution with 2,4-dinitrophenylhydrazine. $^{9 \mathrm{~b}}$ As expected, only benzaldehyde DNPH was isolated, indicating that no alkylidenealkylamine was formed in the course of the catalytic anodic process.

After exhaustive anodic oxidation, the Pt anode was replaced by a mercury pool, because $N$-benzylidene alkylamine could not be reduced at the platinum cathode in methanol. Obviously, the switch to a mercury cathode constitutes a relative weakness of the process from practical and environmental points of view. Replacing the $\mathrm{Hg}$ cathode by a graphite carbon cathode, the yield was roughly halved because of partial loss of the product on the porous graphite carbon material. Achieving both the oxidative amine alkylation and the imine reduction using a single anode/cathode couple would be a challenge for the future. When the potential of the mercury pool was fixed at $-1.6 \mathrm{~V}$ vs SCE, which is at a potential for which $\mathrm{N}$-benzylidenealkylamine could be reduced to the corresponding secondary amine, the UV absorption band at $250 \mathrm{~nm}$ disappeared in agreement with the formation of the secondary amine (See Figure 1(b) in the Supporting information). Note the UV-vis absorption changes recorded in the course of the imine reduction reaction were almost superimposed with those observed during the oxidation-imine formation sequence. Accordingly, the two-electron reduction process led to $N$-benzyl- $N$ cyclopropylmethylamine in $80 \%$ yield (entry 1 , Table 1 ).

In subsequent studies, we examined the scope of the process using different alkylating amines. The results are summarized in Table 1. Various aliphatic primary amines reacted with benzylamine to give the desired products in yields ranging from 51 to $80 \%$. In several cases (entries 26 , entry 8 , entries 11 and 12 , Table 1), dibenzylamine was formed as a by-product. However, the formation of dibenzylamine could be limited to $5-10 \%$, through the addition of an excess of alkylating amine (1.5 equiv).
Table 1. Electrocatalyzed N-alkylation of benzylamine with different primary aliphatic amines. ${ }^{a}$

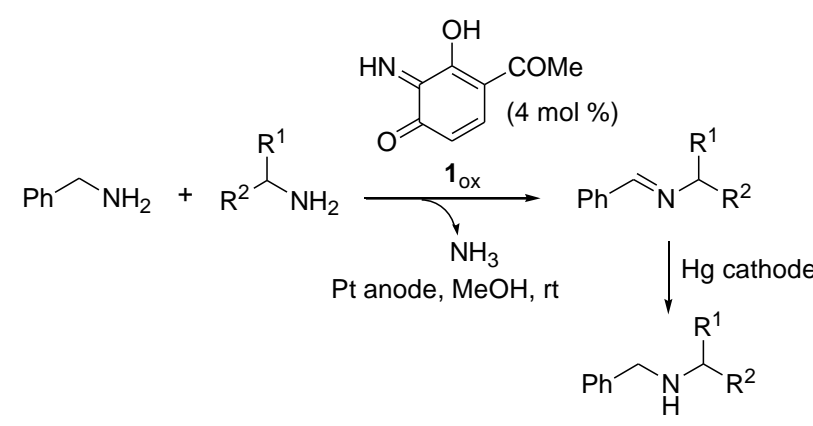

entry alkylating

${ }^{a}$ Reagents and conditions: $\left(\mathbf{1}_{\mathbf{o x}}\right)=0.4 \mathrm{mM}(4 \mathrm{~mol} \%$ relative to benzylamine), (benzylamine) $=10 \mathrm{mM}$, (alkylating amine $)=15 \mathrm{mM}$, $\mathrm{MeOH}$, rt. Oxidation-imine formation step: Pt anode $(\mathrm{E}=+0.6 \mathrm{~V}$ vs $\mathrm{SCE}), 3 \mathrm{~h}$. Imine reduction step: $\mathrm{Hg}$ cathode ( $\mathrm{E}=-1.6 \mathrm{~V}$ vs SCE), $1 \mathrm{~h}$. ${ }^{b}$ Yields refer to chromatographically pure isolated products and are relative to benzylamine. ${ }^{c}$ dibenzylamine was formed as a by-product (5$10 \%) .{ }^{d}$ diamines were observed as by-products $(5-15 \%)$. ${ }^{e}$ diamine was isolated in $30 \%$ yield and was partly formed during work-up.

In some cases (entries 2, 7, 9 and 10, Table 1), diamines arising from a one-electron reduction mechanism were also observed as dimeric by-products. To minimize the formation of these compounds, which were produced after a bimolecular dimerization reaction, 
benzylamine concentration did not exceed $10 \mathrm{mM}$. Furthermore, the application of a sufficiently negative cathodic potential $(-1.6 \mathrm{~V}$ vs SCE) favored the electroreduction of the alkylimine intermediate to the desired secondary amine. ${ }^{11}$

Table 2. Electrocatalyzed N-alkylation of different activated primary amines with phenylpropylamine. ${ }^{a}$

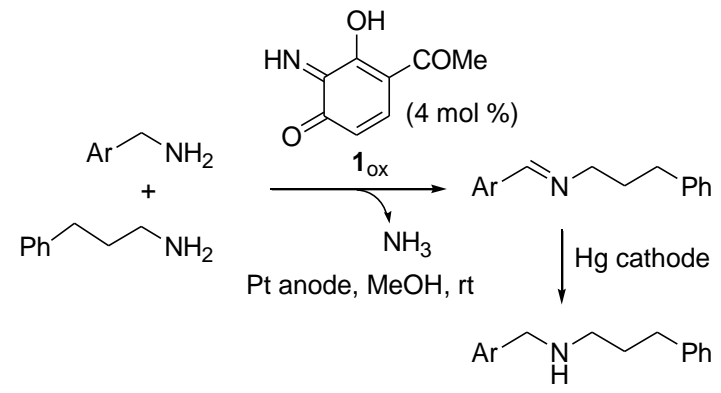

\begin{tabular}{|c|c|c|c|}
\hline entry & $\begin{array}{l}\text { amine } \\
\text { substrate }\end{array}$ & product & ${ }_{b}$ yield $\%$ \\
\hline 1 & & & $68^{c}$ \\
\hline 2 & & & $62^{c}$ \\
\hline 3 & & & $65^{c}$ \\
\hline 4 & & & $68^{c}$ \\
\hline 5 & & & $51^{d}$ \\
\hline 6 & & & $61^{e}$ \\
\hline 7 & & & $56^{e}$ \\
\hline 8 & & & $58^{e}$ \\
\hline
\end{tabular}

${ }^{a}$ Reagents and conditions: (amine substrate) $=10 \mathrm{mM}$, (phenylpropylamine $)=15 \mathrm{mM},\left(\mathbf{1}_{\mathbf{o x}}\right)=0.4 \mathrm{mM}(4 \mathrm{~mol} \%$ relative to the amine substrate), $\mathrm{MeOH}$, rt. Oxidation-imine formation step: Pt anode $(\mathrm{E}=+0.6 \mathrm{~V}$ vs SCE$), 3 \mathrm{~h}$. Reduction step: $\mathrm{Hg}$ cathode $(\mathrm{E}=-1.6 \mathrm{~V}$ vs SCE), $1 \mathrm{~h} .{ }^{b}$ Yields refer to chromatographically pure isolated products and are relative to the amine substrate. ${ }^{c}$ Substituted dibenzylamine was formed as a by-product (5-10\%). ${ }^{d}$ Bis-naphtalen-2-yl-methylamine was isolated as a by-product in $25 \%$ yield. ${ }^{e} N$ (pyridinylmethyl)pyridinemethanamine was formed as a by-product: $4 \%$, entry $6 ; 12 \%$, entry $7 ; 11 \%$, entry 8 .

Interestingly, in the case of $\beta$-aminoalcohols (entries 11 and 12, Table 1), the presence of the alcohol group did not interfere with the catalytic anodic process indicating a good tolerance of this functional group. Furthermore, the use of $(R)-(-)-2$-amino-1-butanol gave the expected aminoalcohol with no loss of optical activity $\left\{[\alpha]^{22}\right.$ -22.0 (c 2.6, EtOH); lit. $^{12}[\alpha]_{\mathrm{D}}^{20}-25.6$ (c 0.08 , EtOH $\left.)\right\}$ as shown in entry 12 . So, the synthesis of various $\beta$ aminoalcohols should be feasible through this one-pot oxidation-imine formation-reduction sequence.

In a second series of experiments, we explored the electrocatalyzed $\mathrm{N}$-alkylation of various activated amine substrates with phenylpropylamine chosen as the alkylating agent (Table 2). As expected, activated substituted benzylamines were good substrates for this reaction, and the product yield did not markedly depend on the substitution of the phenyl ring (entries 1-4, Table 2 ). However, in the case of 1-naphtalenemethylamine, the yield of the desired secondary amine decreased to $51 \%$, while that of bis-naphtalen-2-yl-methylamine increased to $25 \%$ (entry 5, Table 2). Probably, the stability of the symmetrical imine species facilitated its extrusion during the $\mathbf{1}_{\mathbf{o x}}$-mediated catalytic process at the expense of the unsymmetrical expected imine. Less activated pyridinemethanamines could be also $\mathrm{N}$-alkylated with phenylpropylamine by the present biomimetic electrocatalytic system (entries 6-8, Table 2).

Finally, the possibility to apply our methodology to non-activated primary amines was briefly examined using aminomethylcyclopropane as the amine substrate and phenylpropylamine as the alkylating agent (Scheme 2). The yield of isolated product (48\%) was lower than that expected on the basis of the high current efficiency $(95 \%$ for $3 \mathrm{~h}),{ }^{9 \mathrm{a}}$ probably as a result of the lower stability of the produced secondary alkylamine during work-up. However, this moderate yield is redeemed by the simplicity and the rapidity of our approach which could be useful for the assembly of libraries.

Scheme 2. Electrocatalyzed N-alkylation of non-activated aminomethylcyclopropane with phenylpropylamine.

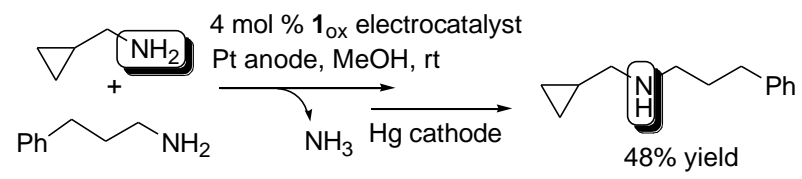

In conclusion, we have developed a facile one-pot metal-free oxidation-imine formation-reduction route to benzylic secondary amines. The key step of the process consisted of the chemoselective $\mathbf{1}_{\mathbf{o x}}$-mediated catalytic oxidation of an activated primary amine, in the presence of a second amine used as the alkylating agent. This atomeconomical sequence, leaving ammonia as the sole byproduct, at both ambient temperature and pressure, should allow the synthesis of various amine derivatives including $\beta$-aminoalcohols. We are currently expanding the scope of this novel reaction sequence.

Supporting Information Available: Figure 1, general experimental procedure, high field ${ }^{1} \mathrm{H}$ NMR spectra for 
known compounds as a criterion of purity, characterization data for new secondary amines, including ${ }^{1} \mathrm{H}$ and ${ }^{13} \mathrm{C}$ NMR spectra. This material is available free of charge via the Internet at http://pubs.acs.org.

(11) The formation of related diamines has already been observed from the one-electron cathodic reduction of aldimines. See for example: (a) Tanaka, H.; Nakahara, T.; Dhimane, H.; Torii, S. Synlett 1989, 51 52. (b) Largeron, M.; Fleury, M.-B. J. Org. Chem. 2000, 65, 88748881. (c) Siu, T.; Li, W.; Yudin, A.K. J. Comb. Chem. 2001, 3, 554558.

(12) (a) Togrul, M.; Turgut, Y.; Hosgoren, H. Chirality 2004, 16, 351-355. (b)Togrul, M.; Askin, M.; Hosgoren, H. Tetrahedron: Asymmetry 2005, 16, 2771-2777. 